\title{
The Role of Executive Function in Children's Mindfulness Experience
}

\author{
Kaitlyn M. Butterfield ${ }^{1}$ (1) $\cdot$ Kim P. Roberts ${ }^{2}$ (])
}

Accepted: 24 November 2021 / Published online: 22 December 2021

(c) The Author(s) 2021

\begin{abstract}
Objectives The effects of a 6-week mindfulness program were examined to assess how executive function level played a role in students' mindful experience. The effects of the mindfulness program were evaluated according to prospective outcomes across students' level of executive function, in comparison to an active control group.

Methods Classrooms were randomly assigned to a mindfulness-based program or a health-based active control group. Pre- and early adolescent students in the 5th to 8th grade $(N=52)$ from two MindfulMe! program classrooms and two HealthyMe! program classrooms (active control group) completed self-reported pre-test and post-test measures to assess mindful attention awareness, strengths and difficulties, anxious arousal, rumination, and optimism. A composite score was created from student-, teacher-, and parent-reported BRIEF2 screening forms to determine students' approximate level of executive function prior to the beginning of the program.

Results There was a significant decrease in rumination for students in the mindfulness-based intervention when compared to the active controls. Findings suggest executive function predicted an individual's change score in total difficulties, mindful attention awareness, optimism, and anxious arousal, after participating in a mindfulness-based intervention.

Conclusions Mindfulness-based interventions appear to particularly benefit those with higher levels of executive function; however, an active control did not variably impact students according to their level of executive function.
\end{abstract}

Keywords Mindfulness $\cdot$ Schools $\cdot$ Executive function $\cdot$ Programming

Mindfulness is associated with a wide range of emotional, physical, and psychological benefits (Atreya et al., 2018; Keng et al., 2011; Schonert-Reichl et al., 2015; Shonin et al., 2014). It has been conceptualized as a state, as experienced during informal or formal mindful practice, and as a trait, characterized as an individual's "predisposition to be mindful in daily life" (Kiken et al., 2015). Researchers believe that repeated mindfulness-based practices contribute to a greater state of mindfulness, thereby improving an individual's trait mindfulness as well (Kiken et al., 2015). The growing appeal to engage young children in mindfulness training is often initiated by research emphasizing a decrease in psychological symptoms and an increase in cognitive abilities

Kim P. Roberts

kroberts@wlu.ca

1 Department of Psychology, Faculty of Health, York University, 4700 Keele Street, Toronto, ON, Canada

2 Department of Psychology, Faculty of Science, Wilfrid Laurier University, 75 University Avenue West, Waterloo, ON, Canada following mindful practice (Keng et al., 2011). Moreover, persistent problems in childhood and early adolescence including aggression, bullying, stress, and mental health problems have drawn attention to potential programs, such as mindfulness-based interventions, in an attempt to reach students in a meaningful way (Schonert-Reichl et al., 2015).

An increase of mindfulness-based programming for children has led to scientific research on the benefits, risks, feasibility, and acceptability of the practice (Atreya et al., 2018; Shonin et al., 2014). Research reports show the positive benefits in children after participating in MBIs such as a decrease in parent-reported externalizing problems (Fung et al., 2016), improved attention and reduced test anxiety (Napoli et al., 2005), reductions in stress responses (Gould et al., 2012; Long et al., 2018; Mendelson et al., 2010), improved emotional and behavioral problems (Joyce et al., 2010; Klatt et al., 2013; Waldemar et al., 2016), improvements in hyperactivity, ADHD symptoms, and cognitive inattention (Klatt et al., 2013), and improvements in depressive symptoms (Schonert-Reichl et al., 2015; Semple et al., 2005; Sibinga et al., 2016). 
The conceptual relation between mindfulness and executive function has recently garnered interest. Executive function refers to top-down mental processes such as inhibitory control, cognitive flexibility, and working memory (Diamond, 2013; Janz et al., 2019). Individuals with higher levels of executive function have been associated with a number of positive outcomes, such as an individual's perceived physical and mental health over time (Brown \& Landgraf, 2010; Centers for Disease Control and Prevention, 2018), while low executive control is related to some learning and behavioral difficulties (e.g., ADHD, Gagne et al., 2019). Individual components of executive function have also been associated with positive outcomes. For example, children with high levels of inhibitory control are less likely to make risky choices, be overweight, have high blood pressure, or have substance abuse problems later in life (Moffitt et al., 2011). Working memory influences cognitive efficiency, learning, and academic performance (Holdnack et al. 2016). Researchers have proposed a relationship between flexible thinking and depressive symptoms, such that greater cognitive flexibility may be associated with the "endorsement of more effective coping strategies" (Gabrys et al., 2018). Researchers have also identified a negative association between rumination and inhibitory control (Yang et al., 2017); it is proposed that learned optimism promotes cognitive flexibility in children (Shatté et al., 1999), and anxious arousal is "evidenced by reductions across all executive function domains" (Warren et al., 2021).

The role of executive function is often described as a psychological process involved in conscious control of action and thought (Riggs et al., 2003). The majority of research focuses on a unidirectional relationship assuming that mindfulness improves executive function (see Mak et al., 2018). Despite the growing evidence for the relationship between mindfulness and executive function, the literature fails to clearly identify the role that cognition has in dispositional mindfulness (Riggs et al., 2015). Given that individuals with lower levels of executive control tend to have trouble suppressing dominant responses to extraneous stimuli, mindfulness may be difficult or impossible for students with lower levels of executive functioning.

The relationship between children's executive function and the effectiveness of a classroom mindfulness-based program on five domains was assessed: mindful attention awareness, awareness of anxiety-induced physiological symptoms, optimism, strengths and difficulties, and rumination. There were two research questions: (1) Does a 6-week mindfulness intervention benefit students in comparison to an active control condition? (2) Does executive function significantly predict change scores in all five outcome measures?

\section{Method}

\section{Participants}

All participants (parents, teachers, children) were required to be able to communicate in English and not have any major developmental delays (to the point of inability to properly assent/consent). All (100\%) participants who indicated interest in the current study (i.e., returned a complete consent form) met the eligibility criteria. Between both participating schools, all students between grades 5-8 $(N=58)$ were given a consent form, 52 took part in the study; six students did not provide adequate written consent and/or verbal assent and their data were therefore not collected. Disproportionate distribution in the current study is due to the nature of both participating schools; one was sport-focused, and one was for students with learning difficulties. Table 1 contains details of demographics between the two groups.

\section{Procedures}

The current study employs a mixed design with program (MindfulMe! vs. HealthyMe!) as a between-subjects variable, time (pre-intervention, post-intervention) as a withinsubjects variable, and composite executive function score

Table 1 Age, gender, ethnic background, and grade distribution by condition (MindfulMe!, control)

\begin{tabular}{|c|c|c|c|c|}
\hline \multirow[t]{2}{*}{ Demographic } & \multicolumn{2}{|c|}{$\begin{array}{l}\text { Mindfulness group } \\
(n=26)\end{array}$} & \multicolumn{2}{|c|}{ Control $(n=26)$} \\
\hline & $\%$ & $n$ & $\%$ & $n$ \\
\hline \multicolumn{5}{|c|}{ Racial background } \\
\hline White & 69.2 & 18 & 69.2 & 18 \\
\hline East Asian & 7.6 & 2 & 0 & 0 \\
\hline Not specified & 23.1 & 6 & 30.8 & 8 \\
\hline \multicolumn{5}{|l|}{ Gender } \\
\hline Female & 23.1 & 6 & 11.5 & 3 \\
\hline Male & 76.9 & 20 & 88.5 & 23 \\
\hline \multicolumn{5}{|l|}{ Age } \\
\hline 9 & 3.8 & 1 & 0 & 0 \\
\hline 10 & 19.2 & 5 & 11.5 & 3 \\
\hline 11 & 46.2 & 12 & 26.9 & 7 \\
\hline 12 & 11.5 & 3 & 34.6 & 9 \\
\hline 13 & 15.4 & 4 & 26.9 & 7 \\
\hline 14 & 3.8 & 1 & 0 & 0 \\
\hline \multicolumn{5}{|l|}{ Grade } \\
\hline Five & 15.4 & 4 & 11.5 & 3 \\
\hline Six & 57.7 & 15 & 19.2 & 5 \\
\hline Seven & 11.5 & 3 & 34.6 & 9 \\
\hline Eight & 15.4 & 4 & 34.6 & 9 \\
\hline
\end{tabular}


as a predictor variable. A cluster (classroom-based)-randomized controlled design was used, with assignment to a mindfulness-based classroom program or health education active control program using the randomization function in Microsoft Excel for Mac. This randomization was conducted by the primary investigator prior to having any contact with participating teachers and students. Each participating school had an intervention group and an active control group (i.e., one classroom was assigned to intervention, one classroom assigned to control). Teachers were not included in any of the activities in the current study-besides having them exit the classroom, no further measures were taken.

A team of four experienced researchers underwent an intensive 1-day training session for either MindfulMe! or HealthyMe!, and they were provided with a program binder outlining each program lesson, the literature behind each activity, and the goals for each session. Detailed scripts were provided to each member of the team with materials to facilitate activities. The MindfulMe! and HealthyMe! instructors taught all sessions in full during a summer camp 1 year prior to the current study with children of comparable ages. There were two researchers for each session. They declared that they had followed the scripts and were asked to note any deviations from the script. There were no deviations reported.

Due to the nature of the intervention, double blinding was not possible to implement. Blinding was limited to program facilitators, parents, teachers, and students having no knowledge of the student's allocation to condition until day one of the program. All coders were blind throughout the entire study and data entry process. As such, all BRIEF2 forms and pre-test outcome measure booklets were completed blind. To ensure the highest level of neutrality, the primary investigator did not attend the school on days where the post-test measures took place. Compensation was provided to the participating school in the form of a lump sum donation of $\$ 50$ plus an additional $\$ 10$ for every participating classroom, regardless of how many students or classrooms agreed to participate. In addition, all teachers were compensated with a \$25 Amazon gift card for completing BRIEF2-T forms for their respective students. No payment or credit was provided to student participants.

The BRIEF2 screening form was administered to students, parents, and teachers approximately 2 weeks prior to the start of the program along with the respective consent form. All BRIEF2 forms were collected at pre-test, and those who had returned completed consent and BRIEF2 forms were then provided with an oral description of the study. The children were asked if they would like to participate in the current study as the pre-test questionnaire duotangs were being handed out. The research associates explicitly assured students that they may withdraw their assent and cease participation without penalty at any time. Over the course of
6 weeks, the students participated in half-hour activity sessions, once a week. A brief description of daily activities was provided prior to starting each program session.

The number of BRIEF2-T forms included in the Teacher package was dependent on the number of students in their respective classrooms (i.e., teachers were asked to fill out a BRIEF2-T for each participating student in their class). The principal investigator provided each participating student with a Parent Package, which comprised the 12-item BRIEF2-P to be reported for their child(ren) and returned the following week. To appraise fidelity to the programs, the sessions were video-recorded, attendance was taken each session, and children self-reported their preferences after the session ended.

\section{MindfulMe! Program}

The MindfulMe! program was informed by guidelines and resources provided by currently available mindfulnessbased programs, such as MindUP (The Hawn Foundation, 2011) and website programs and activities. Once a week, for 6 weeks, children in the MindfulMe! intervention group $(n=26)$ participated in mindful activities with research associates from the Child Memory and Learning Lab, Wilfrid Laurier University. These sessions comprised getting to know each other, relaxation practices, and various activities selected as tools for children to learn how to accept and manage their emotions and subsequent behavior (see Table 2 for details).

\section{HealthyMe! Program}

The HealthyMe! program served as the active control group in this study and was created specifically for this project using resources from a non-profit children's health system database, KidsHealth ${ }^{\circledR}$, one of the largest resources online for medically reviewed health information written for parents, children, and teens. This program was chosen because it had only recently been released and so there was very little chance that children had seen this before. The program focuses on basic hygiene, nutrition, safety, and physical health throughout 6 weekly activity sessions (see Table 3 for further details).

\section{Measures}

Demographic Information Information on demographics were collected through consent forms administered to parents. The data includes child gender, birth date, grade, racial background, and a voluntary declaration of diagnoses for autism spectrum disorder, attention-deficit hyperactivity disorder, obsessive-compulsive disorder, or Tourette's syndrome. The parents of 26 students (thirteen students 
Table 2 MindfulMe! program with weekly activities

\begin{tabular}{|c|c|c|}
\hline Week & Activity & Description \\
\hline 1 & Body scan & $\begin{array}{l}\text { Students learned about the importance of relaxation and breathing techniques and they completed a body } \\
\text { scan. Students were then challenged to do the body scan at least once in the next week }\end{array}$ \\
\hline 2 & Mindful movement & $\begin{array}{l}\text { Students learned to measure their own heart rate. Mindful movements included "poses" such as the but- } \\
\text { terfly pose, rag doll pose, and warrior pose. Students were challenged to do a balancing action at least } \\
1 \times \text { daily over the next week }\end{array}$ \\
\hline 3 & Learning to choose optimism & $\begin{array}{l}\text { Students learned the importance of a positive attitude by training the skill of optimism while remaining } \\
\text { realistic. Students were challenged to make an "optimism framework" at least } 1 \times \text { over the next week }\end{array}$ \\
\hline 4 & Gratitude & $\begin{array}{l}\text { Students wrote what they are thankful for on green cardboard "thankful leaves" that were later combined } \\
\text { to create a "gratitude tree." Students were challenged to name something you are grateful for } 2 \times \text { daily }\end{array}$ \\
\hline 5 & Mindful eating & $\begin{array}{l}\text { Students took part in a visualization exercise where they mindfully imagined eating something sweet, salt, } \\
\text { sour, and bitter. Students were challenged to mindfully eat their lunch that day (immediately following } \\
\text { this activity) }\end{array}$ \\
\hline 6 & Mindful seeing & $\begin{array}{l}\text { Students mindfully looked out their window and described stimuli as if it were the first time (e.g., what } \\
\text { would a bird look like if you've never seen one, describe the shape, color, weight, texture, etc.) }\end{array}$ \\
\hline
\end{tabular}

Table 3 HealthyMe! program with weekly activities

\begin{tabular}{lll}
\hline Week & Activity & Description \\
\hline 1 & Food labels & $\begin{array}{c}\text { Students learned how to interpret food labels and nutrition facts. Students were challenged to choose healthier foods for } \\
1 \text { week }\end{array}$ \\
3 & Peer pressure & $\begin{array}{c}\text { Students learned the difference between positive and negative peer pressure by engaging in a role play. Students were } \\
\text { challenged to identify words affiliated with positive peer pressure and negative peer pressure } \\
\text { Students created a breakfast menu and incorporated healthy food options. Students were challenged to eat one more } \\
\text { healthy breakfast than usual }\end{array}$ \\
4 & Germs & $\begin{array}{l}\text { Students learned about ways to avoid germs such as washing hands. Students created a catchy song, joke, or dance to relay } \\
\text { knowledge to their peers. Students were challenged to wash their hands properly and for the recommended amount of } \\
\text { time }\end{array}$ \\
5 & Cold and flu & $\begin{array}{c}\text { Students discussed how individuals catch colds, what the symptoms are, and how to prevent catching a cold. Students } \\
\text { created a factsheet differentiating the common cold and the flu. Students were challenged to teach one other person the } \\
\text { difference between the cold and flu }\end{array}$ \\
6 & Online safety & $\begin{array}{l}\text { Students learned about fun, educational, and safe online games. Students learned the difference between a safe or poten- } \\
\text { tially unsafe online website. Students were challenged to find a fun and safe website for children }\end{array}$ \\
\hline
\end{tabular}

in MindfulMe! and thirteen students in HealthyMe!) selfidentified that their children had a formal diagnosis of one or more of the following: attention-deficit hyperactivity disorder (ADHD), autism spectrum disorder (ASD), Tourette's syndrome, and obsessive-compulsive disorder (OCD).

Executive Function Students were assessed on their executive functioning according to a self-report (BRIEF2-SR Screening Form), parent report (BRIEF2-P Screening Form), and teacher report (BRIEF2-T Screening Form). The screening forms for students, teachers, and parents contain 12-items and use a 3-point Likert scale ( $\mathrm{N}=$ never, $\mathrm{S}=$ sometimes, $\mathrm{O}=$ often) to measure three items from the BRIEF2 Behavioral Rating Index, four items from the Emotion Rating Index, and five items from the Cognitive Rating Index (Gioia et al., 2016). Higher scores on the composite executive function variable indicate greater levels of potential executive dysfunction. Internal consistency is high, ranging from 0.87 to 0.91 in a standardization sample and 0.80 to
0.89 in a clinical sample (Gioia et al., 2016). In the current study, internal consistency was shown by a high Cronbach's alpha for the BRIEF2-T $(\alpha=0.95)$, BRIEF2-P $(\alpha=0.91)$, and BRIEF2-SR $(\alpha=0.84)$, and the composite executive function score $(\alpha=0.83)$.

As per the screening nature of the administered BRIEF2 forms, a composite score was not available to researchers in the assessment tool itself. To ensure that a robust measure of perceived executive function was calculated, the raw scores across student, parent, and teacher forms were averaged to manually create a single composite score. Raw scores across student, parent, and teacher forms were all positively correlated with one another (Table 4).

To verify the accuracy associated with the composite score created in step one, a point-biserial correlation was conducted between the dichotomous (yes, no) voluntary declaration variable and the continuous composite raw score. According to this calculation, there was a statistically significant correlation between formal diagnoses and 
Table 4 Pearson correlations between the parent-, teacher-, and self-reported BRIEF2

\begin{tabular}{llllllll}
\hline Measure & BRIEF2-T & \multicolumn{3}{c}{ BRIEF2-P } & \multicolumn{2}{c}{ BRIEF2-SR } \\
\hline & $r$ & $p$ & $r$ & & $p$ & $r$ & $p$ \\
BRIEF2-T & & & .644 & $<.001$ & & .650 & $<.001$ \\
BRIEF2-P & .644 & $<.001$ & & & & .634 & $<.001$ \\
BRIEF2-SR & .650 & $<.001$ & .634 & & $<.001$ & &
\end{tabular}

executive function, $\operatorname{rpb}(50)=0.779, p<0.001$, with formally diagnosed students having higher composite executive dysfunction scores (i.e., greater difficulties) than those without formal diagnoses, $M=26.85(S D=0.67)$ vs. $M=18.47$ $(S D=0.68)$.

Strengths and Difficulties To assess participants' strengths and difficulties, a brief behavioral screening self-report questionnaire known as the Strengths and Difficulties questionnaire (SDQ) was used for the present study. The SDQ assess five dimensions of emotional symptoms (5 items), conduct problems ( 5 items), hyperactivity/inactivity ( 5 items), peer problems ( 5 items), and prosocial behavior ( 5 reverse-scored items), in addition to a total difficulties score (sum of all items except prosocial behavior subscale). The total difficulties score has been found to have high internal consistency with a Cronbach's alpha of 0.78 (Roy et al. 2008). Cronbach's alpha for the current study was 0.77 .

Mindful Attention Awareness Scale for Children (MAAS-C) Mindful attention awareness was assessed through the administration of the self-report Mindful Attention Awareness Scale for Children (Lawlor et al., 2013). The current study reverse-scored and summed all items to produce a total dispositional mindfulness score. Higher scores indicate mindfulness whereas lower scores indicate low levels of mindfulness. Cronbach's alpha for the current study was 0.83 .

\section{Children's Response Styles Questionnaire-Rumination Scale} Revised (CRSQ-RSR) The 25-item self-report Children's Response Styles Questionnaire (CRSQ-RSR; Abela et al. 2004) is an age-appropriate version of the Response Styles Questionnaire (Nolen-Hoeksema and Morrow 1991). The current study used the rumination subscale of the CRSQRSR to evaluate the tendency for participants to engage in repetitive thoughts about the cause of their distress (du Pont et al. 2019). A 13-item rumination subscale of the CRSQ is used to rate items ranging from $1=$ almost never, $2=$ sometimes, $3=$ often, to $4=$ almost always. A total score is achieved by summing all items, with higher scores indicating stronger ruminative response style. In a sample of primary school students, Cronbach's alphas ranged from 0.55 to 0.86 (Verstraeten et al. 2010). Cronbach's alpha for the current study was 0.88 .
Resiliency Inventory (RI) The original RI created by Noam and Goldstein (1998) was modified by Song (2003). The measure is used to assess six dimensions of resilience: optimism, relationship with peers, relationships with adults, self-efficacy, interpersonal sensitivity, and emotional control. The current study only used the optimism subscale to assess participants' self-reported positive present and future perspective on the world (Schonert-Reichl \& Lawlor, 2010). The 10-item optimism scale is rated on a 5-point Likert scale by participants, ranging from $1=$ not at all like me, $2=\mathrm{a}$ little bit like me, $3=$ kind of like me, $4=$ a lot like me, to $5=$ always like me. Higher scores represent greater optimism. Song (2003) has shown high internal consistency for the optimism subscale, according to a Cronbach's alpha of 0.84. Cronbach's alpha for the current study was 0.62 .

\section{Mood and Anxiety Symptom Questionnaire-Anxiety Arousal} (MASQ-AA) The current study administered a modified version of the scale, specifically consisting of the 10-item Anxious Arousal subscale (ANXAR) used to assess the extent to which participants experience physiological symptoms with minimal association to general negative affect such as anger, disgust, and contempt (Hankin 2009). These 10 items were chosen in accordance with Hankin (2008) who conducted a factor analysis on the broader 17 items and found these 10 to be the highest loading on the ANXAR factor. Students rated themselves on each of the 10 items on a scale ranging from $1=$ not at all, $2=$ a little bit, $3=$ moderately, $4=$ quite a bit, to $5=$ extremely. The total score was the sum of all 10 items, with higher scores on the MASQ-AA reflecting higher anxious arousal and lower scores reflecting lower anxious arousal. Reliability and validity of the MASQ-AA have been shown in previous literature (e.g., Hankin et al. 2008; Watson et al. 1995). Cronbach's alpha for the current study was 0.86 .

\section{Data Analyses}

Three values were found unreported for the MAAS-C in the active control group only (missing data $=$ no response to an item on the scale). In the current study, all missing values were replaced by the series mean. The current study employed a linear regression model and used SPSS v25(C. Analyses of variance were completed with outcome variables (total difficulties, mindful attention awareness, 
rumination, optimism, anxiety arousal) as the dependent variables and time (pre-test, post-test) and condition (MindfulMe!, HealthyMe!) as independent variables, and time was within-subjects.

Executive function scores are presented in Table 5. To examine whether change scores are predicted by student levels of executive function, linear regressions were run with composite executive function score as the continuous predictor, and change scores for students' mindful attention awareness, strengths and difficulties, mood and anxiety symptoms, rumination, and optimism as dependent variables.

\section{Results}

\section{Preliminary Analyses}

To establish baseline equivalence between conditions, an analysis of variance was conducted to assess whether statistical differences existed on pre-test measures between conditions. No significant condition differences were found

Table 5 Means and standard deviations for BRIEF2 executive function measures by program (MindfulMe!, control) and report type (teacher, parent, self-report)

\begin{tabular}{lll}
\hline & MindfulMe $(n=26)$ & Control $(n=26)$ \\
\hline Teacher (BRIEF2-T) & $22.58(8.16)$ & $20.88(6.36)$ \\
Parent (BRIEF2-P) & $22.81(6.63)$ & $22.31(5.98)$ \\
Self (BRIEF2-SR) & $24.27(5.54)$ & $23.4(4.32)$ \\
\hline
\end{tabular}

at pre-test for the BRIEF2-T, BRIEF2-P, BRIEF2-SR, composite executive function score, SDQ, MAAS-C, RI, CRSQ-RSR, or MASQ-AA (largest $F$ was associated with the CRSQ-RSR; $F=0.442, \mathrm{p}=0.509$ ).

\section{Strengths and Difficulties}

There was no statistically significant interaction between the conditions and time on total difficulties, $F(1,50)=1.129$, $p=0.293, \eta_{\mathrm{p}}{ }^{2}=0.022$ (see Table 6 for means and standard deviations). However, the main effect of time showed a statistically significant decrease in mean total difficulties at the different time points, $F(1,50)=35.128, p<0.001$, $\eta_{\mathrm{p}}{ }^{2}=0.413$ (pre-test $M=20.19, S D=0.94$; post-test $M=15.37, S D=1.07)$. The main effect of condition did not show a statistically significant difference in mean total difficulties between conditions, $F(1,50)=2.044$, $p=0.159, \eta_{\mathrm{p}}{ }^{2}=0.039\left(M_{\text {MindfulMe! }}=19.10, S D=1.30\right.$; $\left.M_{\text {HealthyMe! }}=16.46, S D=1.30\right)$.

\section{Mindful Attention Awareness}

There was no statistically significant interaction between the conditions and time on mindful attention awareness, $F(1,50)=0.007, p=0.931, \eta_{\mathrm{p}}{ }^{2}=0.000$ (see Table 6 for means). The main effect of time showed a statistically significant increase in mean mindful attention awareness at the different time points, $F(1,50)=8.986, p=0.004$, $\eta_{\mathrm{p}}{ }^{2}=0.152$ (pre-test $M=54.21, S D=1.79$; post-test $M=58.21, S D=2.06$ ). The main effect of condition did not show a statistically significant difference in mean mindful
Table 6 Means and standard deviations for outcome measures by program (MindfulMe!, control) and time (pre, post)

\begin{tabular}{|c|c|c|c|c|}
\hline & \multicolumn{2}{|c|}{ MindfulMe! $(n=26)$} & \multicolumn{2}{|c|}{ HealthyMe! $(n=26)$} \\
\hline & Pre-test & Post-test & Pre-test & Post-test \\
\hline \multicolumn{5}{|l|}{ Total difficulties } \\
\hline Emotional problems & $4.46(2.61)$ & $5.15(2.99)$ & $3.23(2.30)$ & $4.04(2.66)$ \\
\hline Conduct problems & $3.69(1.55)$ & $3.19(2.40)$ & $3.81(1.94)$ & $2.54(2.20)$ \\
\hline Hyperactivity & $6.69(1.85)$ & $5.23(2.16)$ & $6.27(2.39)$ & $4.50(2.23)$ \\
\hline Peer problems & $6.19(2.00)$ & $3.38(2.42)$ & $6.00(1.94)$ & $2.42(2.04)$ \\
\hline Prosocial & $7.58(1.81)$ & $8.08(1.57)$ & $7.38(2.53)$ & $7.62(2.32)$ \\
\hline Internalizing score & $10.65(4.17)$ & $8.54(5.06)$ & $9.23(3.31)$ & $6.46(4.43)$ \\
\hline Externalizing score & $10.38(3.14)$ & $8.42(4.12)$ & $10.08(3.98)$ & $7.04(3.95)$ \\
\hline \multicolumn{5}{|l|}{ MAAS-C } \\
\hline $\begin{array}{l}\text { Total Mindfulness Score } \\
\text { CRSQ-RSR }\end{array}$ & $54.46(12.22)$ & $58.58(13.98)$ & $53.96(13.53)$ & $57.85(15.64)$ \\
\hline Total Rumination Score & $23.35(5.73)$ & $19.38(7.45)$ & $22(8.58)$ & $21.35(7.36)$ \\
\hline \multicolumn{5}{|l|}{ RI-Optimism } \\
\hline $\begin{array}{l}\text { Total Optimism Score } \\
\text { MASQ-AA }\end{array}$ & $44(7.18)$ & $45.62(7.05)$ & $47.35(7.93)$ & $45.27(8.32)$ \\
\hline Total Anxiety Arousal Score & $21.62(7.89)$ & $19.31(9.22)$ & $22.54(10.05)$ & $21.04(8.20)$ \\
\hline
\end{tabular}


attention awareness between conditions, $F(1,50)=0.029$, $p=0.866, \eta_{\mathrm{p}}{ }^{2}=0.001\left(M_{\text {MindfulMe! }}=56.52, S D=2.56\right.$; $\left.M_{\text {HealthyMe! }}=55.90, S D=2.56\right)$.

\section{Children's Response Styles Questionnaire- Rumination Scale Revised}

There was a statistically significant interaction between conditions and time on rumination scores, $F(1,50)=7.842$, $p=0.007, \eta_{\mathrm{p}}{ }^{2}=0.136$ (see Table 6 for means). The main effect of time showed a statistically significant decrease in mean rumination at the different time points, $F(1$, $50)=15.268, p<0.001, \eta_{\mathrm{p}}{ }^{2}=0.234$ (pre-test $M=22.67$, $S D=1.01$; post-test $M=20.37, S D=1.03$ ). The main effect of condition did not show a statistically significant difference in mean rumination between conditions, $F(1,50)=0.025$, $p=0.875, \eta_{\mathrm{p}}{ }^{2}=0.000\left(M_{\text {MindfulMe! }}=21.37, S D=1.38\right.$; $\left.M_{\text {HealthyMe! }}=21.67, S D=1.38\right)$.

Separate $t$-tests were conducted to further investigate the significant interaction. There was a significant difference in the rumination scores from pre-test $(M=23.35, S D=5.73)$ to post-test $(M=19.38, S D=7.45)$ in the MindfulMe! condition; $t(25)=5.569, p=0.000$, Cohen's $d=0.598)$. In contrast, no significant differences were found in the rumination scores from pre-test $(M=22.0, S D=8.58)$ to posttest $(M=21.35, S D=7.36)$ in the HealthyMe! condition; $t(25)=0.693, \mathrm{p}=0.494$, Cohen's $d=0.081$. Thus, students in the MindfulMe! condition decreased in rumination significantly more than their peers in the HealthyMe! program did.

\section{Resiliency Inventory (RI)}

There was a statistically significant interaction between the conditions and time on optimism, $F(1,50)=4.880, p=0.032$, $\eta_{\mathrm{p}}{ }^{2}=0.089$ (see Table 6 for means). The main effect of time did not show a statistically significant difference in mean optimism at the different time points, $F(1,50)=0.076$, $p=0.784, \eta_{\mathrm{p}}{ }^{2}=0.002$. The main effect of condition also did not show a statistically significant difference in mean optimism between conditions, $F(1,50)=0.593, p=0.445$, $\eta_{\mathrm{p}}{ }^{2}=0.012$.

Separate $t$-tests were conducted to further investigate the significant interaction. No differences were found in the optimism scores from pre-test $(M=44.0, S D=7.18)$ to post-test $(M=45.62, S D=7.05)$ in the MindfulMe! condition, $t(25)=-1.598, p=0.123$, Cohen's $d=0.228$; nor the HealthyMe! condition, $t(25)=1.560, p=0.131$, Cohen's $d=0.256$ (pre-test $M=47.35, S D=7.93$; post-test, $M=45.27, S D=8.32$ ). The most logical reason for the significant interaction is that, while children in both conditions scored 45 on average at post-test, this represented a slight decrease (from 47) in optimism for those in the MindfulMe! condition and a slight increase for those in the HealthyMe! condition. Caution is urged, however, given the results of the follow-up $t$-tests.

\section{Mood and Anxiety Symptoms Questionnaire- Anxiety Arousal}

A statistically significant interaction was not found between the conditions and time on anxiety arousal, $F(1,50)=0.237$, $p=0.628, \eta_{\mathrm{p}}{ }^{2}=0.005$. The main effect of time showed a statistically significant decrease in mean anxiety arousal at the different time points, $F(1,50)=5.271, p<0.026, \eta_{\mathrm{p}}{ }^{2}=0.095$. The main effect of condition did not show a statistically significant difference in mean anxiety between conditions, $F(1,50)=0.327$, $p=0.570, \eta_{\mathrm{p}}{ }^{2}=0.007$ (see Table 5 for means and SDs).

In summary, students in both programs increased in mindful attention and decreased in difficulties and anxiety. The MindfulMe! condition decreased in rumination significantly while their peers in HealthyMe! did not. Furthermore, even though optimism means appear to change from pre- to post-test, the $t$-test was not significant.

\section{Executive Function and Mindfulness}

\section{Strengths and Difficulties}

A linear regression was used to predict the total difficulties change score $=-10.997+0.303 *$ composite executive function. The composite executive function score was a statistically significant predictor of the total difficulties change scores, $F(1,24)=7.102, p=0.014$, accounting for $22.8 \%$ of the variation in total difficulties change scores with adjusted $R^{2}=19.6 \%$, a small-medium size effect according to Cohen (1988). Notably, a single increase $(+1)$ in an individual's composite executive function score leads to a $0.303,95 \%$ CI $[0.068,0.538]$ increase in total difficulties change score. This means that smaller decreases in difficulties were seen with children with lower executive function scores compared to larger decreases for those with higher executive function scores. A linear regression was also conducted to determine the effect of executive function on total difficulties after a health-based intervention. The composite executive function score did not predict total difficulties change scores in the active control group, $F(1,24)=0.023, p=0.882$.

\section{Mindful Attention Awareness}

A linear regression was used to predict the mindful attention awareness change score $=15.636-0.496 *$ composite executive function. The composite executive function score statistically significantly predicted mindful attention awareness change scores, $F(1,24)=5.473, p=0.028$, accounting for $18.6 \%$ of the variation in mindfulness attention awareness change scores with adjusted $R^{2}=15.2 \%$, a small-medium 
size effect according to Cohen (1988). Notably, a single increase $(+1)$ in an individuals' composite executive function score leads to a $0.496,95 \%$ CI $[-0.934,-0.058]$ decrease in mindful attention awareness change score.

A linear regression was also conducted to determine whether executive function affected mindful attention awareness after a health-based intervention. The composite executive function score did not predict mindful attention awareness change scores in the active control group, $F(1$, $24)=0.187, p=0.669$, and was not expected to.

\section{Children's Response Styles Questionnaire- Rumination Scale Revised}

A linear regression was used to predict the rumination change score $=-13.589+0.415^{*}$ composite executive function. The composite executive function score statistically significantly predicted rumination change scores, $F(1$, $24)=24.546, p<0.001$, accounting for $50.6 \%$ of the variation in rumination change scores with adjusted $R^{2}=48.5 \%$, a large effect size according to Cohen (1988). Notably, a single increase $(+1)$ in an individuals' composite executive function score leads to a $0.415,95 \%$ CI $[0.242,0.587]$ increase in rumination change score.

A linear regression was also conducted to determine the effect of executive function on rumination after a healthbased intervention. The composite executive function score did not predict rumination change scores in the active control group, $F(1,24)=3.156, p=0.088$.

\section{Resiliency Inventory-Optimism Subscale}

To determine the effect of executive function on optimism after a mindfulness-based intervention, a linear regression was computed. The composite executive function score did not statistically significantly predict optimism change scores, $F(1,24)=0.253, p=0.620$.

A linear regression was also conducted to determine the effect of executive function on optimism after a health-based intervention. The composite executive function score did not statistically significantly predict optimism change scores in the active control group either, $F(1,24)=0.008, p=0.931$.

\section{Mood and Anxiety Symptom Questionnaire-Anxiety Arousal}

A linear regression was used to predict the anxiety arousal change score $=-7.350+0.217 *$ composite executive function. The composite executive function score statistically significantly predicted anxiety arousal change scores, $F(1$, $24)=4.934, p=0.036$, accounting for $17.1 \%$ of the variation in anxiety arousal change scores with adjusted $R^{2}=13.6 \%$, a small size effect. Notably, a single increase $(+1)$ in an individuals' composite executive function score leads to a $0.217,95 \%$ CI $[0.015,0.419]$ increase in anxiety arousal change score.

A linear regression was also conducted to determine the effect of executive function on anxious arousal after a health-based intervention. The composite executive function score did not predict anxious arousal change scores in the active control group, $F(1,24)=0.324, p=0.574$.

In summary, the findings suggest that executive function is a significant predictor of strengths and difficulties, mindful attention awareness, rumination, and anxiety arousal change scores, but did not predict optimism change scores. Executive function was not related to change scores for those in the HealthyMe! condition.

\section{Discussion}

The study evaluated the impact of executive function on the psychological, behavioral, and physiological outcomes of elementary school students who were randomized to a mindfulness-based intervention or a health-based intervention. It was expected that, regardless of executive function, students in the mindfulness-based intervention would show greater improvements pre- to post-test in total difficulties, mindful attention awareness, rumination, optimism, and anxious arousal, in comparison to an active control group. It was further expected that executive function would significantly predict the extent that a student would benefit from the mindfulness-based intervention, according to outcome variable gain scores.

After a 6-week intervention, decreased rumination was observed in children in the MindfulMe! condition in comparison to children in the control condition. Significant differences between conditions were not observed for total difficulties, mindful attention awareness, optimism, or anxious arousal. Thus, when the potential outcomes of mindfulness practice are compared to another intervention where the program length and materials are similar in style, there are fewer effects of mindfulness than seen in the literature. This highlights the importance when selecting control groups. Positive mindfulness effects may be overestimated when compared to a "treatment-as-usual" (TAU) control.

When the findings are considered with respect to past literature, it suggests that there may be a latent factor influencing the non-significant differences found in this study and other studies (Schonert-Reichl \& Lawlor, 2010). More specifically, and in line with the current study, it is possible that executive function may play a role in non-significant findings in mindfulness-based research, such that significant differences between intervention and controls may be diminished when there are participants with difficulties in executive function. For example, if half of an intervention group 
includes students with ADHD, ASD, learning disorders, or other difficulties, their results have the potential to skew data collected within the classroom as a whole. In this instance, research tends to present non-significant findings without acknowledging the significant benefits that may be occurring for some students as well as the difficulties experienced by the students who did not benefit from the program at all or as much as their peers.

The role of executive function was subsequently tested to further an understanding of its role in mindfulness-based interventions and its effects on potential benefits. The set of linear regressions established the predictive ability of executive function when looking at change scores (pre- to post-test) of students who participated in MindfulMe! and in HealthyMe!. The results suggest that differences in executive functioning may be one reason why significant differences were not found for the overwhelming majority of outcome variables. According to the results, the focus should not only be on why mindfulness does not appear to significantly target outcomes when compared to an active control, but just as importantly on the underlying characteristics of participants and whether these characteristics are preventing the benefits of mindfulness-based interventions to take full effect.

In summary, a 6-week classroom-based mindfulness intervention may not be beneficial or accessible to all students. The current study demonstrates that executive function may significantly predict the extent that a student will benefit from a mindfulness-based intervention in all areas (anxiety arousal, mindful attention awareness, rumination, total difficulties) except optimism. This finding is important to consider when evaluating the cognitive faculties required for children to benefit from mindfulness-based interventions, such that decreases in rumination appears to be accessible to all students regardless of their executive function in the current study. Further research with a larger sample size is clearly warranted to conclusively state that current mindfulness interventions and their activities are well-equipped to decrease rumination in all students.

\section{Limitations and Future Directions}

It has been long asserted that there are limitations associated with self-report measures in behavioral research, notwithstanding the difficulties introduced when the self-reporter is a child participant (Goodman et al., 2017). Bias in selfreport measures is found to be an even larger issue in mindfulness research (Goodman et al., 2017). Participants who have increased in their mindfulness may be more aware of their behavior, thoughts, and intentions, which then translates into rating themselves lower on self-report measures. This notable "reverse bias effect" would not take place in active control group participants, rendering any significant differences between the two groups difficult to interpret
(Goodman et al., 2017). Participants in the mindful condition were exposed to familiar "context clues" in the questionnaire that they would have encountered during mindful activities and may have reinstated memories of these concepts therefore eliciting a biased response. To counteract this, data from the BRIEF2 was included from multiple informants to reduce an overwhelming bias effect.

Second, and in addition to the self-report measures for outcome variables, research has asserted the limitations associated with measures of executive function in children (Ledochowski et al., 2019). The difficulties associated with task-based measures of executive function include the inability to distinguish which component of EF is being used, whereas self-report measures of executive function are unable to capture the real-world responses that a taskbased measure would. There is also concern for the lack of correlation between measures of executive function in past research (Ledochowski et al., 2019). Future research would therefore benefit from using a combination of task-based and self-report measures of executive function, to ensure they correlate prior to drawing conclusions. Also, the full BRIEF2 could be used rather than a screening form, to allow for a more componential analysis of executive function.

Third, the sample size and diversity were largely limited due to circumstances beyond the researcher's control, as the participating schools in the current study were specifically oriented toward two niche groups of students. The first school catered to students with learning difficulties and the second school catered to students in competitive hockey. Therefore, the current study is limited in its ability to generalize any significant findings beyond these populations as they may not fully represent a typical classroom. Future research might benefit extensively from a larger sample size, namely through the analysis of a wider variety of schools (i.e., private, public, faith-based, etc.).

The MindfulMe! program was facilitated by trained research assistants. This serves as a potential barrier to acceptability such that students may not be as receptive to learning about mindfulness from an external facilitator rather than their teacher with whom they are familiar. Therefore, the current study may only be generalizable to programs that are facilitated by an external individual. However, it is important to note the barriers associated with teacher-delivered mindfulness interventions including additional training and planning for an already full teaching plan, and the unrealistic expectations for all teachers to become specialists in mindfulness.

Method bias is a limitation of the current study, such that multiple constructs are being measured using common methods (multiple item scales presented in the same questionnaire). Asking participants to report their experience on two or more constructs in the same questionnaire is likely to produce spurious correlations among the items measuring 
these constructs by means of response styles, social desirability, and priming effects which are independent from the true correlations among the constructs being measured (Podsakoff et al., 2012).

Finally, while the inclusion of clinical populations is inevitable when researching a range of executive functioning, the current study did not have access to full diagnostic information for ethical reasons. Knowing more information about students who have been formally diagnosed with a disorder associated with executive dysfunction, such as their medication intake, treatment/therapy history, date of diagnosis, name of diagnosis, and any other relevant information, may be important when assessing individual differences in the potential benefits off mindfulness-based interventions.

Author Contribution KB: designed and executed the study, completed the data analyses, and wrote the first draft of the paper. KR: collaborated with the design, analysis, writing, and submission of the manuscript. Both authors approved the final version of the manuscript for submission.

Data Availability Participants were not informed that the data would be deposited in an accessible repository. The data are stored at Wilfrid Laurier University in K Roberts' lab on a password-protected computer.

\section{Declarations}

Ethics The research was reviewed by the Institutional Research Board at Wilfrid Laurier University and was deemed to be ethically sound. Guardians provided informed consent and children gave verbal assent.

Conflict of Interest The authors declare no competing interests.

Open Access This article is licensed under a Creative Commons Attribution 4.0 International License, which permits use, sharing, adaptation, distribution and reproduction in any medium or format, as long as you give appropriate credit to the original author(s) and the source, provide a link to the Creative Commons licence, and indicate if changes were made. The images or other third party material in this article are included in the article's Creative Commons licence, unless indicated otherwise in a credit line to the material. If material is not included in the article's Creative Commons licence and your intended use is not permitted by statutory regulation or exceeds the permitted use, you will need to obtain permission directly from the copyright holder. To view a copy of this licence, visit http://creativecommons.org/licenses/by/4.0/.

\section{References}

Atreya, C. E., Kubo, A., Borno, H. T., Rosenthal, B., Campanella, M., Rettger, J. P., Joseph, G., Allen, E., Venook, A. P., Altschuler, A., \& Dhruva, A. (2018). Being present: A single-arm feasibility study of audio-based mindfulness meditation for colorectal cancer patients and caregivers. PLoS ONE, 13(7), e0199423. https://doi. org/10.1371/journal.pone.0199423

Brown, T. E., \& Landgraf, J. M. (2010). Improvements in executive function correlate with enhanced performance and functioning and health-related quality of life: Evidence from 2 large, double-blind, randomized, placebo-controlled trials in ADHD. Postgraduate Medicine, 122(5), 42-51. https://doi.org/10.3810/ pgm.2010.09.2200

Diamond, A. (2013). Executive functions. Annual Review of Psychology, 64(1), 135-168. https://doi.org/10.1038/jid.2014.371

Fung, J., Guo, S., Jin, J., Bear, L., \& Lau, A. (2016). A pilot randomized trial evaluating a school-based mindfulness intervention for ethnic minority youth. Mindfulness, 7(4), 819-828. https://doi. org/10.1007/s12671-016-0519-7

Gabrys, R. L., Tabri, N., Anisman, H., \& Matheson, K. (2018). Cognitive control and flexibility in the context of stress and depressive symptoms: The cognitive control and flexibility questionnaire. Frontiers in Psychology, 9, 1-19. https://doi.org/10.3389/ fpsyg.2018.02219

Gagne, J. R., Chang, C., Fang, H., Spann, C., \& Kwok, O. (2019). A multimethod study of inhibitory control and behavioral problems in preschoolers. Infant and Child Development, 28(1), 16. https://doi.org/10.1002/icd.2115

Goodman, M. S., Madni, L. A., \& Semple, R. J. (2017). Measuring mindfulness in youth: Review of current assessments, challenges, and future directions. Mindfulness, 8(6), 1409-1420. https://doi.org/10.1007/s12671-017-0719-9

Gould, L. F., Dariotis, J. K., Mendelson, T., \& Greenberg, M. T. (2012). A school-based mindfulness intervention for urban youth: Exploring moderators of intervention effects. Journal of Community Psychology, 40(8), 968-982.

Janz, P., Dawe, S., \& Wyllie, M. (2019). Mindfulness-based program embedded within the existing curriculum improves executive functioning and behavior in young children: A waitlist controlled trial. Frontiers in Psychology. Retrieved from https:// www.frontiersin.org/article/10.3389/fpsyg.2019.02052

Joyce, A., Etty-Leal, J., Zazryn, T., \& Hamilton, A. (2010). Exploring a mindfulness meditation program on the mental health of upper primary children: A pilot study. Advances in School Mental Health Promotion, 3(2), 17-25. https://doi.org/10.1080/ 1754730X.2010.9715677

Keng, S. L., Smoski, M. J., \& Robins, C. J. (2011). Effects of mindfulness on psychological health: A review of empirical studies. Clinical Psychology Review, 31(6), 1041-1056.

Kiken, L. G., Garland, E. L., Bluth, K., Palsson, O. S., \& Gaylord, S. A. (2015). From a state to a trait: Trajectories of state mindfulness in meditation during intervention predict changes in trait mindfulness. Personality and Individual Differences, 81, 41-46. https://doi.org/10.1016/j.paid.2014.12.044

Klatt, M., Harpster, K., Browne, E., White, S., \& Case-Smith, J. (2013). Feasibility and preliminary outcomes for Move-IntoLearning: An arts-based mindfulness classroom intervention. The Journal of Positive Psychology, 8(3), 233-241. https://doi. org/10.1080/17439760.2013.779011

Lawlor, M. S., Schonert-Reichl, K. A., Gadermann, A. M., \& Zumbo, B. D. (2013). A validation study of the mindful attention awareness scale adapted for children. Mindfulness, 5(6), 730-741. https://doi.org/10.1007/s12671-013-0228-4

Ledochowski, J., Andrade, B. F., \& Toplak, M. E. (2019). A novel unstructured performance-based task of executive function in children with attention-deficit/hyperactivity disorder. Journal of Clinical and Experimental Neuropsychology, 41(5), 445-459. https://doi.org/10.1080/13803395.2019.1567694

Long, A. C. J., Renshaw, T. L., \& Camarota, D. (2018). Classroom management in an urban, alternative school: A comparison of mindfulness and behavioral approaches. Contemporary School Psychology, 22, 233-248. https://doi.org/10.1007/ s40688-018-0177-y

Mak, C., Whittingham, K., Cunnington, R., \& Boyd, R. N. (2018). Efficacy of mindfulness-based interventions for attention and executive function in children and adolescents-a systematic 
review. Mindfulness, 9(1), 59-78. https://doi.org/10.1007/ s12671-017-0770-6

Mendelson, T., Greenberg, M. T., Dariotis, J. K., Gould, L. F., Rhoades, B. L., \& Leaf, P. J. (2010). Feasibility and preliminary outcomes of a school-based mindfulness intervention for urban youth. Journal of Abnormal Child Psychology, 38(7), 985-994. https://doi.org/10.1007/s10802-010-9418-x

Moffitt, T. E., Arseneault, L., Belsky, D., Dickson, N., Hancox, R. J., Harrington, H., ... Caspi, A. (2011). A gradient of childhood self-control predicts health, wealth, and public safety. Proceedings of the National Academy of Sciences, 108(7), 2693 LP 2698. https://doi.org/10.1073/pnas.1010076108

Napoli, M., Krech, P. R., \& Holley, L. C. (2005). Mindfulness training for elementary school students. Journal of Applied School Psychology, 21(1), 99-125. https://doi.org/10.1300/J370v21n01_05

Podsakoff, P. M., MacKenzie, S. B., \& Podsakoff, N. P. (2012). Sources of method bias in social science research and recommendations on how to control it. Annual Review of Psychology, 63, 539-569.

Riggs, N. R., Black, D. S., \& Ritt-Olson, A. (2015). Associations between dispositional mindfulness and executive function in early adolescence. Journal of Child and Family Studies, 24(9), 2745-2751. https://doi.org/10.1007/s10826-014-0077-3

Riggs, N. R., Blair, C. B., \& Greenberg, M. T. (2003). Concurrent and 2-year longitudinal relations between executive function and the behavior of 1st and 2nd grade children. Child Neuropsychology, 9(4), 267-276. https://doi.org/10.1076/chin.9.4.267.23513

Schonert-Reichl, K. A., Oberle, E., Lawlor, M. S., Abbott, D., Thomson, K., Oberlander, T. F., \& Diamond, A. (2015). Enhancing cognitive and social-emotional development through a simpleto-administer mindfulness-based school program for elementary school children: A randomized controlled trial. Developmental Psychology, 51(1), 52-66. https://doi.org/10.1037/a0038454

Schonert-Reichl, K. A., \& Lawlor, M. S. (2010). The effects of a mindfulness-based education program on pre-and early adolescents' well-being and social and emotional competence. Mindfulness, 1(3), 137-151.

Semple, R., Reid, E., \& Miller, L. (2005). Treating anxiety with mindfulness: An open trial of mindfulness training for anxious children. Journal of Cognitive Psychotherapy, 19, 379-392. https://doi.org/10.1891/088983905780907702

Shatté, A. J., Reivich, K., Gillham, J. E., \& Seligman, M. E. P. (2015). Learned optimism in children. Oxford University Press. https:// doi.org/10.1093/med:psych/9780195119343.003.0008

Shatté, A. J., Reivich, K. J., Gillham, Jane and Seligman, M. E. P. (1999). Learned Optimism In Children. Coping: The psychology of what works. 165-181. https://doi.org/10.1093/med:psych/ 9780195119343.003.0008

Shonin, E., Gordon, W. V., \& Griffiths, M. D. (2014). Are there risks associated with using mindfulness in the treatment of psychopathology? Clinical Practice, 11(4), 389-392. https://doi.org/10. $2217 / \mathrm{cpr} .14 .23$

Sibinga, E. M., Webb, L., Ghazarian, S. R., \& Ellen, J. M. (2016). School-based mindfulness instruction: An RCT. Pediatrics, 137(1), https://doi.org/10.1542/peds.2015-2532. https://doi.org/ 10.1542/peds.2015-2532

The Hawn Foundation. (2011). MindUP curriculum: Brain-focused strategies for learning - and living. Scholastic Inc.

Waldemar, J. O. C., Rigatti, R., Menezes, C. B., Guimarães, G., Falceto, O., \& Heldt, E. (2016). Impact of a combined mindfulness and social-emotional learning program on fifth graders in a Brazilian public school setting. Psychology \& Neuroscience, 9(1), 79-90.

Warren, S. L., Heller, W., \& Miller, G. A. (2021). The structure of executive dysfunction in depression and anxiety. Journal of Affective Disorders, 279, 208-216. https://doi.org/10.1016/j.jad.2020. 09.132

Yang, Y., Cao, S., Shields, G. S., Teng, Z., \& Liu, Y. (2017). The relationships between rumination and core executive functions: A meta-analysis. Depression and Anxiety, 34, 37-50. https://doi. org/10.1002/da.22539

Publisher's Note Springer Nature remains neutral with regard to jurisdictional claims in published maps and institutional affiliations. 